\title{
Dünyada ve Türkiye'de Tütün Kullanımı ve Tütün Kontol Politikalarına Genel Bir Bakış
}

\author{
Tobacco Use of the World and in Turkey and Tobacco Control Policy an Overview
}

\author{
Süleyman Furkan Pesen' \\ Seyfullah Karadoğan ${ }^{2}$ \\ ${ }^{1}$ Int. Dr., Gazi Üniversitesi Tıp Fakültesi, Ankara, Türkiye, drsfpesen@gmail.com \\ 2 Int. Dr., Gazi Üniversitesi Tıp Fakültesi, Ankara, Türkiye, semsur124@hotmail.com \\ ${ }^{3}$ Int. Dr.,Gazi Üniversitesi Tıp Fakültesi, Ankara, Türkiye, aykutakbulut.004@gmail.com
}

Aykut Akbulut

Öz

Tütün kullanımı tüm ülkeler için en önemli halk sağlığı problemlerinin başında gelmektedir. Derlememizde dünyada ve Türkiye'de tütün kullanımı, maddi manevi sonuçları, kullanımın azaltımasına yönelik politikalar, politikalar kapsamında yapılan mücadele programları ve alınan sonuçlar konusunda bilgi vermek amaçlanmıştır. Dünyada ve Türkiye'de en sık bağımlılık yapıcı, oldukça yaygın kullanılan bir madde olan tütün ürünlerinin sebep olduğu can kayıpları, her türlü zararlar ülkelerin tütünle mücadele konusuna önem vermelerini gerektirmiştir. Aynı zamanda tütün kontrol politikası kapsamında MPOWER paketi hakkında bilgi verilmesi amaçlanmaktadır. Dünyada ve Türkiye'de mücadele kapsamında neler yapıldığı hakkında bilgiler verilmiştir. Tütün kullanımının sağlığa etkisi, yaptığı hastalıklar değerlendirilerek bu kapsamda bu hastalıkların oluşturduğu maddi ve manevi olumsuzluklar değerlendirilmiştir. Tütün kullanımının meydana getirdiği morbidite ve mortalitelerin ülkelere oluşturduğu ekonomik yük hakkında da bilgiler ele alınmıştır. Tütün kullanımının sadece kullanan kişiler için değil daha büyük bir çevreyi etkilediği, pasif etkilenenlerin durumu hakkında bilgiler verilmiştir. Yine tütünle mücadele kapsamında Tütün Kontrolü Çerçeve Sözleşmesi (TKÇS),ülkemizde 2006'da gündeme alınan Ulusal Tütün Kontrol Programı (UTKP) hakkında da bilgiler verilmesi amaçlanmıştır.

Anahtar Kelimeler: Tütün, Sağlık, Tütün Kontrolü, Epidemiyoloji.

\begin{abstract}
Using tobacco is one of the most important public health problem for all countries. In this review, Turkey and world tobacco using statistic, moral consequences, politics of diminishing usage of tobacco, accomplished works with these politics and results is that we wish to give information.The life loss of the most addicted and most worldwided material, which is tobacco, is given most important thing of fighting against it.With this regard, MPOWER pack which is politics of controlling tobacco will be given information about it.In the world and Turkey, we will give knowledge about what is done which regards of tobacco. Health consequences of tobacco, diseases which is caused by tobacco, and physical and moral consequences of these diseases will be recovered.Economic trouble of mortality and morbidity of tobacco using is given information also.Tobacco using is also effects passive smokers, we will give knowledge about that.In addition Framework Convention on Tobacco Control (FCTC) and National Tobacco Control Program (NTCP) will be introduced to you.
\end{abstract}

Keywords: Tobacco, Health, Tobacco Control, Epidemiyology. 


\section{GiRiş}

Tütün ürünleri: Hammadde olarak tamamen ya da kısmen tütün yaprağından üretilmiş; çiğneyerek, emerek, buruna çekerek ya da tüttürerek gibi yollarla kullanılan otsu bir bitkinin ürünleridir. Tütün ürünlerine örnek olarak sigara, puro, nargile, bidi, pipo, çiğneme tütünü, sarma tütünü, snus, guthka tütünü verilebilir. Türkiye'de ve dünyada en sık kullanılan bağımlılık yapıcı ürünlerin başında gelen tütün her yıl çok sayıda can kaybına sebep olmanın yanı sıra maddi ve manevi sorunlara yol açması sebebiyle uluslararası tütünle mücadele önem kazanmıștır. Hem ulusların kendi içlerinde aldığı önlem ve yasalar hem uluslararası tütünle mücadele kapsamında imzalanan sözleșmeler tütün kullanımını en aza indirmeyi hedeflemektedir.

\section{DÜNYADA TÜTÜN KULLANIMI}

\section{Dünyada Tütün Kullanım Prevelansı}

Tütün kullanımı dünyada oldukça yaygın görülen ve bağımlılık potansiyeli yüksek bir davranıştır. Dünya genelinde 1.5 milyar dolaylarında insan tütün ve tütün ürünleri kullanmaktadır. Çin, Hindistan ve Endonezya gibi ülkeler tütün kullanımında başı çekmektedir. Türkiye ise 17 milyon dolaylarında $(\% 31,2)$ kişi sayısı ile ilk 10 ülke arasında bulunmaktadır. Bu 10 ülke dünyada tütün kullanımının 3'te 2'sini oluşturmaktadır. Tütün kullanımı bakımından gelișmiș ülkelerde bu oran gelișmekte olan ülkelere göre çok düșüktür. Ancak farklı bir durum olarak gelişmişülkelerdeki kadınların sigara içme oranı gelişmekte olan ülkelere göre daha yüksek saptanmaktadır. Gelişmiş ülkelerde kadın ve erkeklerin tütün kullanım oranları birbirine çok yakınken gelişmekte olan ülkelerde bu oran çok farklılık göstermektedir(Yılmaz, 2006).

\section{Dünyada Tütün Kullanımın Ekonomiye Etkisi}

Tütün kullanımı nedeniyle gerçekleşen prematür ölümler, hastalıklar, verimlilik kayıpları ve sağlık bakım harcamaları küresel maliyette 1,4 trilyon dolarlık kayıp oluşturmaktadır. ABD'de sigara kullanımına bağı gelişen hastalıkların oluşturduğu maliyetin toplam sağlık harcamaları içerisindeki yeri \%6(yaklaşık 8 milyar dolar) olarak ölçülmüştür.(Çalışkan \& Metintaş, 2018).

\section{Dünyada Tütün Kullanımının Kontrolü}

Devletler tütün kullanımının önlenmesi ve bunların etkilerinin azaltılması amacıyla pek çok yerel ve ulusal politika uygulayabilmektedir.2003 yılında hayata geçirilen Tütün Kontrolü Çerçeve Sözleșmesi (TKÇS) ile dünyada tütün ürünleri ve sigara kullanımasının gün geçtikçe artmış olması, halk sağlığını tehdit edecek boyutlara ulaşması ve tütün sektöründeki stratejilerin tütüne olan ilgiyi arttırması gibi sorunların önlenmeleri amaçlanmıştır. Tütün Koruma Çevre Sözleşmesi ilk uluslararası anlaşma niteliğindedir. Dünya Sağlık Örgütü ve TKÇS tarafları taahhütlerini bildirerek tütün kullanım oranını azalttığı ispatlanmış TKÇS ve DSÖ önerilerine ve ölçütlerine göre hazırlanmış olan MPOWER paketi sunulmuştur.(Başol \& Songül, 2015).

Ocak 2004'te bir grup sağlık meslek birliği DSÖ'de resmi olmayan bir toplantıda bir araya gelerek sağlık personelleri için tütün kontrolü uygulama kılavuzunu geliştirdiler.14 maddeden oluşan bu kılavuzda sağlık örgütlerinin tütün ürünleri bağımlıı̆ının önlenmesi ve bırakılması konusunda potansiyel rolü, sigarasız bir meslek uygulaması amacına yönelik çeşitli şekillerdeki etkinlik ve rehberlikler içermektedir(Organization, 2005).

\section{TÜTÜN KONTROL POLITIKASINDA MPOWER PAKETi}

\section{M (MONITÖR)/ IZLEM:}

- Tüm yaşlarda tütün kullanımının izlenmesi

- Tütün ürünlerinin zararları konusunda bilgilendirme öneri ve uyarı çalışmalarının izlenmesi

- Sigara ve tütün ürünlerinin fiyat artışlarının vergi artırımlarının izlenmesi

- Sigara reklamlarının teşvik edecek promosyonları ve bunlarla ilgili sponsorlukların izlemi

- Sigaraya yönelik koruyucu önlem çalışmalarının izlemi

- Sigara ve benzeri tütün ürünlerinin bırakılması konusunda yapılan yardımların izlenmesi

\section{P(PROTECT) /KORUMA:}

- Insanların sigara dumanına maruz kalmasına yönelik korumalar

- İş yerlerinde sigara dumanına maruz kalınmasına yönelik alınması gereken koruma önlemleri

- Restoranlar ve alışveriş merkezleri dahil kapalı kamusal alanlarda dumansız bir ortam oluşturmaya yönelik korumalar

- Eğitim kurumlarında sigara içilmemesine yönelik koruma önlemleri

- Sağlık kurumlarında sigara kullanımının önlenmesine yönelik korumalar

\section{O(OFFER)/ÖNERILER:}

- Telefondan sigara bırakma hatları yoluyla sigara bırakmaya yönelik çalışmalar 
- İlaç tedavileri ile sigara bıraktırma çalışmaları

- Sigara bırakma konusunda eğitim çalışmaları

- Tedavilere ulaşım konusunda kolay ulaşılabilir hale getirilmesi

\section{W(WARN)/ UYARILAR:}

- Sigara ile ilgili medya kampanyaları

- Paketlerin üzerine yazılan uyarıcı yazı ve resimlerin düzenlenmesi

- Tütün kullanımı karşıtı reklam çalışımları

\section{E(ENFORCE) /YASAKLA:}

- Tütün ve ürünleri satışı konusunda yaş sınırlaması getirilmesi

- Tütün konusunda yasal düzenlemeler yapılarak sponsorluk promosyon ve reklam yapılmasının engellenmesi

\section{R(RAISE) /VERGILENDIRME:}

- Tütün ve ürünlerinin yasadışı ticareti konusunda önlenmesine yönelik vergi düzenlemesi

- Kullanımı azaltmaya yönelik sigara fiyatı ve vergilerinin arttırılmasına yönelik çalışmalar(Raporu, 2008)

\section{TÜRKIYEDE TÜTÜN KULLANIM PREVELANSI}

\section{Yetişkinlerde Tütün Kullanımı}

Türkiye'de sigara kullanım sıklığı hakkında yapılan ilk çalışma 1988 yılında yapılmıştır. Bu çalışmaya göre yetişkinlerin \%44'ü sigara kullanmaktadır. Sigara kullanım sıklığı erkeklerde \%63 kadınlarda \%24 olarak saptanmıştır.1995,1998,1999 yıllarında da çalışmalar devam etmiştir. $\mathrm{Bu}$ çalışmaların tümünde erkeklerde sigara kullanım sıklığının kadınlara göre daha yüksek olduğu görülmüştür.

2003 yılında Türkiye'de ulusal hane halkı çalışması yapılmıştır. Bu çalışmadaki sonuçlara göre ise 18 yaş ve üzerinde sigara kullanım sıklığı \%33,8 olarak saptanmıştır. Sigara kullanımı başlangıç yaşı ise ortalama 19 olarak görülmüştür.

2006 Türkiye İstatistik Kurumu verilerine göre 18 yaş üstü yetişkinlerde sigara kullanım sıklığı erkeklerde \%50,6 kadınlarda \%16,6 olarak saptanmıştır. Pasif etkilenim yüzdesi ise 52,4 olarak görülmüştür. Bir diğer önemli nokta Türkiye'de birçok gelişmiş ülkenin aksine eğitim seviyesi arttıkça sigara kullanım oranı da artmaktadır.(Bilir, Çakır, Dağı, Ergüder, \& Önder, 2010) .

\section{Gençlerde Tütün Kullanımı}

Gençler tütün kullanımı için potansiyel müşterilerdir. $\mathrm{Bu}$ açıdan tütün endüstrisi için oldukça önem arz etmektedirler. Gençlerde kullanım sıklığının araştırılması da önemlidir.

2003,2009,2012,2017 yıllarında KGTA(Küresel Gençlik Tütün Araştırması, GYTS) yapılmıştır. $\mathrm{Bu}$ çalışmaya göre gençlerin genelinde en az bir defa sigara tüketimini deneyenlerin oranı 2003;2009;2012;2017 yıllarına göre sırasıyla \%26,3;\%29,6;\%32,4;\%28,0 olarak saptanmıştır. Gençlerde halen tütün tüketim oranı ise $2003 ; 2009 ; 2012 ; 2017$ yıllarında sırasıyla \%8,4;\%11,9;\%16,8;\%17,9 olarak gerçekleştiği görülmüştür. Hem en az bir defa deneyenlerde hem de halen tütün kullanımına devam edenlerde oran erkeklerde kadınlara göre daha yüksek olarak gerçekleşmiştir(Saraçoğlu \& Öztürk, 2020).

Gençlerde tütün kullanımı azımsanamayacak kadar fazladır. Tütün kullanımına başlamada özellikle yakın arkadaş etkisi önemlidir. Bir diğer etken ise ailenin tütün kullanımına karşı aldığı tavırdır(Bilir et al., 2010).

\section{TÜTÜN KULLANIMININ SAĞLIĞA ETKISi}

\section{Tütünle İlgili Mortalite Ve Morbitide}

Sigara dumanında 4000'den fazla antijenik, mitojeniik, karsinojenik olan madde vardır(Karlıkaya, Öztuna, Solak, Özkan, \& Örsel, 2006).

Türkiye'de tütün kullanımına bağlı ölümlerde kalp damar hastalıkları ve kanser ölümleri önemli bir yer almaktadır. Kalp damar hastalıklarının üçte biri; akciğer, lariks, özofagus, serviks kanserlerinin ise \%37,1'i tütün ilişkili olarak kabul edilmektedir. Tütün kullanımına bağlı gelişen kanser ilişkili mortalite oranı 7 kat artmıştır(Akdeniz, 2019). Kronik obstrüktif akciğer hastalığı(KOAH) tütün kullanımına bağı gelişen bir diğer hastalıktır. Türkiye'de tütün kullanımı sonucu gelişen solunum sistemi hastalığ yükü \%8,9 olarak hesaplanabilir. Sonuçta bu hastalıkların mortaliteye neden olduğu görülebilir ancak değerler birçok kritere göre tahmini olarak hesaplanmaktadır(Bilir et al., 2010).

Tütün kullanımı mortaliteye sebep olmasının yanında önemli bir morbidite sebebidir. Tütün kullanımı 50 kadar kronik hastalıkla ilişkilidir. Bu kronik hastalıklara kanserler, kronik obstrüktif akciğer hastalığı(KOAH),kalp damar hastalıkları dışında periferik ateroskleroz, beyin damar hastalıkları örnek verilebilir. Tütün kullananlarda direkt hastalık yapıcı etki dışında astım, hipertiroidi, kronik 
nezle, multipl skleroz, diabetes mellitus gibi hastalıkların bulgularını dahada ağırlaştırma; inflamatuar bağırsak hastalığı, tüberküloz, pnömoni gibi hastalıkları daha inatçı hale getirme; ejakulasyon bozukluğu, doğurganlıkta azalma, bağışıklık sisteminde zayıflama, erken menapoz gibi işlev bozukluklarına neden olma şeklinde morbiditeler oluşturmaktadır(Karlıkaya et al., 2006).Tütün kullanımına bağlı gelişen bu morbiditeler tütünü bırakmakla ciddi şekilde azalmaktadır. Örneğin tütün bırakıldıktan 3-9 ay sonra nefes darlığı, öksürük azalır,1 yıl sonra kalp krizi riski \%50 azalı,5 yıl sonra akciğer kanseri riski \%50 azalır,10-15 yıl sonra ise risk hiç kullanmamış kişilerin düzeyine iner(Tuncer, Özgül, Olcayto, Gültekin, \& Erdin, 2009).

\section{Tütüne Bağlı Pasif Tüketimin Sağlığa Etkisi}

Tütün kullanımı sonucunda kişinin dışarıya üflediği duman ciğerlerine çektiği dumandan iki kat fazla katran ve nikotin içermektedir. Pasif etkilenime maruz kalan bireylerde aktif kullananlar gibi sağlık problemi yaşamaktadır. Örneğin pasif etkilenime maruz kalan çocuklarda astım, bronşit, soğuk algınlı̆ı, orta kulak problemleri, minokokal enfeksiyon ,alt solunum yolu enfeksiyonları riski artmıştır.

Pasif etkilenim sadece dumanlardan kaynaklanmaz. Örneğin tütün kullanan annelerde düşük doğum ağırlıklı bebek dünyaya getirme riski; emziren annelerin bebeklerinde ise dalgınlık, bronşit, pnömoni riski artmıştır. (Bülbül \& Ceyhun, 2006)

\section{Tütün Kullanımının Covid-19 Hastalarına Etkisi}

Tütün kullanımı Covid-19 hastalığının ağır seyri ve mortalitesi açısından önemli risk faktörüdür. Örneğin Covid-19 hastalarında hastaneye yatışı 2,3 kat; hastalığın ağır seyretme riskini ise 1,91 kat artırmıştır(Arpacıoğlu \& Ünübol, 2020).

\section{TÜRKIYE'DE TÜTÜN KULLANIMININ EKONOMIK YÖNÜ}

Tütün kullanımı kişinin sağlığı açısından ağır kayıplara neden olmanın yanında ekonomik açıdan da kişi ve devletlere ağır bedellere yol açmaktadır.

Tütün kullanımına bağı Türkiye'nin 8-10 milyar dolar zararı olduğu hesaplanmaktadır(Başol \& Songül, 2015).

Bu konuda Türkiye'de yapılan araştırma sayısı az olmasına rağmen 2003 yılında yapılan bir araştırmada bir hasta için yapılan harcama 10.000 ABD doları olarak hesaplanmıştır. Türkiye'de yıllık sadece akciğer kanseri sayısı 40.000 kişi olması ekonomik kaybın ne denli çok olduğunu gözler önüne sermektedir. Tütün tüketimine bağı oluşan diğer hastalıklar, erken ölümler kişilerin iş yapamama durumlarından gelen kayıplar da unutulmamalıdır(Bilir et al., 2010).

\section{TÜRKIYE'DE TÜTÜN KONTROLÜ}

Tütün kullanımının Türkiye'de bireyler arasında sık olması, tütün kullanımı sonucunda oluşan sağlık problemleri ve bu problemlerin gerek bireylere gerek devlete yüklediği kayıplar kontrol politikalarının geliştirilmesini kaçınılmaz hale getirmiştir. Bu amaçla 5 Temmuz 2007 tarihinde Sağlık Bakanlığına bağlı Tütün ve Bağımlılık Yapıcı Maddelerle Mücadele Şubesi kurulmuştur. Aynı zamanda tütün kontrolü için Türkiye'de yapılan ilk yasal düzenleme olan Tütün Mamüllerinin Zararlarının Önlenmesine Dair Kanun(26 Kasım 2006,Sayı 22829)çıkartılııştır.56. Dünya Sağlık Asamble'since onaylanan Tütün Kontrolü Çerçeve Sözleşmesi T.B.M.M tarafından 30 Kasım 2004'te onaylanmıştır.7 kasım 2006 tarihinde ise Ulusal Tütün Kontrol Programı Başbakanlık Genelgesinde yayınlanmış ve Türkiye'de sigara kullanımının 15 yaş üstünde \%20 ,15 yaş altında ise \%0'a inmesi amaçlanmıştır(Bilir et al., 2010).

\section{Bir Başlangıç: Tütün Kontrolü Çerçeve Sözleșmesi}

Dünya genelinde bir milyarı aşkın kiși tütün kullanmaktadır. Özellikle düşük orta gelirli ülkelerde tütün kullanımı daha yaygındır. Bu durum tütünle mücadelede küresel yaklaşımı kaçınılmaz kılmıştır. Bir dönüm noktası olarak kabul edilen Tütün Kontrolü Çerçeve Sözleşmesi(TKÇS) Dünya Sağlık Örgütü(DSÖ) tarafından 2003'te kabul edilmiştir. Türkiye bu sözleşmeyi imzalayan 43. ülkedir. Günümüzde bu sözleşmeyi kabul eden ülkeler tüm dünya nüfusunun $\% 90$ 'ını oluşturmaktadır. Tütün Kontrolü Çerçeve Sözleşmesi(TKÇS) hükümetlerin tütün kullanımını azaltmak için kanıta dayalı politikalar izlemesini zorunlu kılarak mücadeleye yön vermiştir. Tütün Kontrolü Çerçeve Sözleşmesi(TKÇS) ile tütün kullanımının halk sağlığı problemi olduğu, sosyoekonomik olarak düşük seviyeli bireylerde etkisinin daha ağır olabildiği, kadın ve gençlerin kullanımının artması nedeniyle mücadelenin önemli olduğu, bağımlılık yapıcı etkisiyle bizzat hastalık kabul edilmesi gerektiği, pasif etkilenimle geniş kitlelere de etki ettiği, tütün sponsorluklarının önlenmesi gerektiği, ülke içerisinde mücadelede koordinasyon ve işbirliğinin önemli olduğu net bir şekilde vurgulanmaktadır(Aslan, 2005).

\section{Türkiye'de Ulusal Tütün Kontrol Programı}

7 Kasım 2006 tarihinde Başbakanlık Genelgesiyle Ulusal Tütün Kontrol Programı(UTKP) yayınlanması sonrasında 2008-2012,2015-2018 ve en son 2018-2023 yılları arasında uygulanmak üzere Ulusal Tütün Kontrol Programı 
Eylem Planı yayınlanarak yürürlüğe girmiştir.2008-2012 dönemi için yayınlanan Ulusal Tütün Kontrol Programı Eylem Planında 10 temel madde vardır:

- Tütün tüketiminin sağlık üzerinde yarattığı olumsuz etkiler hakkında toplumun bilgilendirilmesi ve bilinçlendirilmesi,

- Sigara tüketiminin bırakılmasının sağlanması,

- Fiyat ve vergilendirmenin artırıması,

- Bireylerin tütün tüketiminden pasif etkileniminin önlenmesi,

- Tütün ürünleri ile ilgili reklam, promosyon ve sponsorluğun yasaklanması,

- Tütün ürünlerinin kontrolü ve tüketicinin bilgilendirilmesi,

- Tütün ürünlerinin yasa dışı ticaretinin engellenmesi,

- Gençlerin tütün ürünlerine ulaşabilirliğinin engellenmesi,

- Tütün üretiminin azaltılması ve alternatif politikaların üretilmesi,

- Tütün tüketimi ve kontrol yöntemlerinin izlenmesi ve değerlendirilmesidir".

$\mathrm{Bu}$ başılılar diğer eylem planlarında da yer almaktadır(Saraçoğlu \& Öztürk, 2020).Söz konusu başlıklarla birlikte birçok hedefte belirlenmiştir.2008-2012 Eylem planının hedeflerine yönelik yapılan değerlendirmede bu hedeflerin birçoğuna ulaşılamadığı görülmüştür. Hedeflerin yerine getirilememesinde bu planda otoriterler ile uygulayıcılar arasında eşgüdümün sağlanamaması, planın yasal dayanağı olan TKÇS(Tütün Kontrolü Çerçeve Sözleșmesi)'nin hükümlerine uyma taahhütünün olmaması, bütçe tahsilleri, kurumsal yapılarca tanımlanmama, denetimlerin etkinleştirilememesi etkili olduğu söylenebilir(Elbek, 2016).2015-2018 eylem planında da 2008-2012 eylem planında olduğu gibi benzer problemler olmasına rağmen gelinen noktada Türkiye önemli gelişmeler göstermiştir(Ekerbiçer, Berberoğlu, \& İnci, 2018).2008-2012 yılları arasında tütün kullanım sıklığı Türkiye'de \%31,2'den \%27,1' e inmiştir.2014 te \%32,5 e yükselmiş ancak bu değer 2016'da \%31,6 seviyesine doğru inmiştir(Bakanlığı, 2018).

2018-2023 Ulusal Tütün Kontrol Programı Eylem Planııın nihai amacı "Toplumdaki tüm bireyleri, tütün ürünlerinin sağlık, ekonomik, çevresel ve sosyal zararlarından korumak" şeklinde belirlenmiştir(Bakanlığı, 2018).Bu nihai amaca yönelik geçmiş eylem planlarına benzer amaçlar, bu amaçlara yönelik yeni hedefler belirlenmiştir. Diğer eylem planlarından elde edilen tecrübeler göz ardı edilmemelidir. $\mathrm{Bu}$ planlamada yillık net hedefler belirlenmesi diğer planlardan farklı olarak göze çarpmaktadır.

\section{SONUÇLAR VE ÖNERILER}

Tütün ve tütün ürünlerinin kullanımı tüm dünyada ve ülkemizde çok yaygınlaşmış durumda olan bir halk sağlığı sorunu durumundadır.

Dünya genelinde 1 milyarı aşkın bir nüfus tarafından tütün ve tütün ürünleri kullanıldığı düşünüldüğünde nasıl bir halk sağlığı sorunu olduğu ,ne kadar büyük bir tehdit oluşturduğu daha net bir şekilde gözler önüne serilmektedir.

Tütün kullanımı kişinin sağlığı açısından ağır kayıplara neden olmanın yanında ekonomik açıdan da kişi ve devletlere ağır bedellere yol açmaktadır.

Düşük ve orta gelirli ülkelerde daha yaygın kullanılan tütün ve tütün ürünleri; mücadelenin çok daha kuvvetli, sistematik, küresel çapta olmasını gerektirmiştir. Bu bağlamda 2003 yılında hayata geçirilen ve DSÖ tarafından da kabul edilen Tütün Kontrolü Çerçeve Sözleşmesi(TKÇS) bu mücadelelerde önemli bir kilometre taşı olup olumlu sonuçlar alınabilmiştir.

Tütün Kontrolü Çerçeve Sözleşmesi(TKÇS) tütün kullanımının bağımlıık yapması sebebiyle hastalık olarak kabul edilmesi, önemli bir halk sağlığı sorunu olması, sadece kullanan kişilerde değil çevrelerini de etkilemesi, artan kullanım oranlarına dikkat edilmesi gerektiği konularında uyarıcı olması noktasında önemli görülmüştür.

Özellikle genç nüfusun tütün ve tütün ürünleri kullanımı noktasında potansiyel olarak en güçlü müşteri grubu olduğu görülmüştür. Bu bağlamda tütün ve tütün ürünlerinin günümüzde çok büyük bir endüstri alanı olduğu göz önünde bulundurulduğunda gençlerin bu potansiyeli bu sektör için önemli bir nokta haline gelmiştir. Yine gençlerde tütün kullanım oranlarının çok yüksek olduğu düşünüldüğünde sebepleri araştırılmıştır. Bu sebepler arasında özellikle bulunulan arkadaş ortamının etkisi ve ailenin bu duruma bakış açısı göze çarpmaktadır.

MPOWER paketi kapsamlı öneriler sunmaktadır. Bu paket kapsamındaki öneriler günümüzde oldukça yaygınlaşan telefon ve iletişim ağları üzerinden sigara bırakma hatları kurulması; ilaç tedavilerine dair bilgiler ve tedavilerinin uygulanması; sigara bırakma konusunda çeşitli eğitimler, seminerler konferanslar verilmesi; tedavilerin geliştirilmesi, yaygınlaştıııması ve kolay ulaşılabilir olması şeklindedir. 


\section{ÖNERILER}

Önümüzdeki yıllarda tütün ve tütün ürünlerini yıkıcı etkisi çok daha ciddi boyutlara gelecek gibi durmaktadır. Bu bağlamda mortalite, morbidite ve ekonomik yönlerden ağır sonuçlarla karşı karşıya kalacağımız muhtemeldir. Tütün kontrolü birçok bileşenden oluşan başta devlet görevi olmak üzere birçok alanın bulunması gereken multidisipliner, multifaktöriyel bir program ișidir. Yine toplumun eğitilmesi noktasında hekimler bașta olmak üzere sağlık eğiticileri, sivil toplum kuruluşları, dernekler aktif roller alabilirler.

Ülkemiz tütün ile mücadele noktasında ağır sonuçlarla her zaman karşı karşıyadır, bu anlamda 2008 itibariyle yakalanan olumlu ivmenin devam etmesi, MPOWER paketi başta olmak üzere önerilere ağırlık verilip uygulanmaya devam etmesi ülkemiz için olmazsa olmazdır.

\section{KAYNAKLAR / REFERENCES}

- Akdeniz, E. (2019). Sigara Bağımlılığı Sağığa Etkileri ve Sigara Bıraktırmada Kullanılan Transteoretik Model. Kırşehir Ahi Evran Üniversitesi Sağlık Bilimleri Dergisi 2, 11-25.

- Arpacıoğlu, S., \& Ünübol, B. (2020). Koronavirüs Salgınında Alkol-Sigara Kullanımındaki Değișiklikler ve Illişkili Durumların Araştırıması. Kıbrıs Türk Psikiyatri ve Psikoloji Dergisi, 2(3), 128138.

- Aslan, D. (2005). Dünyada ve Türkiye'de tütün kontrolünde yeni bir dönem başladı: Tütün Kontrolü Çerçeve Sözleşmesi. Sürekli Tıp Eğitimi Dergisi, 14(1), 19-21.

- Bakanlığı, S. (2018). Tütün Kontrolü Strateji Belgesi ve Eylem Planı (2018-2023). Ankara, Sağlık Bakanlığı.

- Başol, E., \& Songül, C. (2015). Tütün Tüketiminin Ekonomik Etkileri Ve Tütün Kontrol Politikaları Üzerine Bir İnceleme. Balkan Sosyal Bilimler Dergisi, 4(7).

- Bilir, N., Çakır, B., Dağlı, E., Ergüder, T., \& Önder, Z. (2010). Türkiye'de tütün kontrolü politikaları. World Health Organization Report. Available from: URL: http://www. euro. who. int/document E, 93038.

- Bülbül, H. S., \& Ceyhun, G. (2006). Pasif sigara içiciliği. Türkiye Aile Hekimliği Dergisi, 10(3), 123-128.

- Çalışkan, S., \& Metintaş, S. (2018). Dünyada Tütün Kontol Uygulamalarının Küresel Ölçekte Değerlendirilmesi. ESTÜDAM Halk Sağlığı Dergisi, 3(1), 32-41.

- Ekerbiçer, H. Ç., Berberoğlu, U., \& İnci, M. B. (2018). Dumansız bir çevre mücadelesi: dünden bugüne. Sakarya Tıp Dergisi, 8(3), 470-474.

- Elbek, O. (2016). Ulusal Tütün Kontrol Eylem Planı (2015-2018)“Değerlendirme ve Öneriler”. Sürekli Tıp Eğitimi Dergisi, 25, 36-42.

- Karlıkaya, C., Öztuna, F., Solak, Z. A., Özkan, M., \& Örsel, O. (2006). Tütün kontrolü. Toraks dergisi, 7(1), 51-64.

- Organization, W. H. (2005). Tütün kontrolünde sağlık profesyonellerinin rolü. Tütünsüz Yaşam Derneği. Ankara. pp, $1-20$.
- Raporu, D. K. T. S. (2008). MPOWER paketi. Cenevre, Dünya Sağlık Örgütü.

- Saraçoğlu, S., \& Öztürk, F. (2020). Türkiye'de Tütün Kontrol Politikaları ve Tütün Tüketimi Üzerine Bir Değerlendirme. Politik Ekonomik Kuram, 4(1), 20-44.

- Tuncer, M., Özgül, N., Olcayto, E., Gültekin, M., \& Erdin, B. (2009). TC Sağlık Bakanlığı Kanserle Savaş Dairesi Başkanlığı. Ulusal Kanser Programı, 2015.

- Yılmaz, A. (2006). Türkiye de tömbeki üretimi ve nargile kullanımının incelenmesi.(Tez). Ankara: TAPDK. 